\title{
Optimizing Antibiotic Stewardship in Nursing Homes: A Narrative Review and Recommendations for Improvement
}

\author{
Christopher J. Crnich ${ }^{1,2} \cdot$ Robin Jump $^{3,4} \cdot$ Barbara Trautner $^{5,6}$. \\ Philip D. Sloane ${ }^{7,8} \cdot$ Lona Mody ${ }^{9,10}$
}

Published online: 28 August 2015

(C) The Author(s) 2015. This article is published with open access at Springerlink.com

\begin{abstract}
The emerging crisis in antibiotic resistance and concern that we now sit on the precipice of a post-antibiotic era have given rise to advocacy at the highest levels for widespread adoption of programmes that promote judicious use of antibiotics. These antibiotic stewardship programmes, which seek to optimize antibiotic choice when clinically indicated and discourage antibiotic use when clinically unnecessary, are being implemented in an increasing number of acute care facilities, but their adoption has been slower in nursing homes. The antibiotic prescribing process in nursing homes is fundamentally different from that observed in hospital and clinic settings, with formidable challenges to implementation of effective antibiotic stewardship. Nevertheless, an emerging body of research points towards ways to improve antibiotic prescribing practices in nursing homes. This review summarizes the findings of this research and presents ways in which antibiotic stewardship can be implemented and optimized in the nursing home setting.
\end{abstract}

Christopher J. Crnich

cjc@medicine.wisc.edu

1 School of Medicine and Public Health, University of Wisconsin, 1685 Highland Avenue, MFCB 5217, Madison, WI 53705, USA

2 William S. Middleton Veterans Affairs Hospital, Madison, WI, USA

3 Geriatric Research, Education and Clinical Center, Division of Internal Medicine, Louis Stokes Cleveland Department of Veterans Affairs Medical Center, Cleveland, OH, USA

4 Division of Infectious Disease, Department of Medicine, Case Western Reserve University, Cleveland, OH, USA

5 Section of Infectious Diseases, Department of Medicine, Baylor College of Medicine, Houston, TX, USA

\section{Key Points}

The antibiotic prescribing process in nursing homes is complex and differs from the prescribing process in hospital and clinic settings.

Improvements in the quality of antibiotic prescribing in nursing homes have been achieved through a variety of antibiotic stewardship interventions.

Implementing and sustaining antibiotic stewardship in nursing homes requires an organizational commitment and a strategy based on goal setting, process and outcome measurement, and continuous quality improvement.

6 Center for Innovations in Quality, Effectiveness, and Safety, Michael E. DeBakey VA Medical Center, Houston, TX, USA

7 Cecil G. Sheps Center for Health Services Research, University of North Carolina at Chapel Hill, Chapel Hill, NC, USA

8 Department of Family Medicine, University of North Carolina at Chapel Hill, Chapel Hill, NC, USA

9 Division of Geriatric and Palliative Care Medicine, University of Michigan, Ann Arbor, MI, USA

10 Geriatric Research Education and Clinical Center, Veterans Affairs Ann Arbor Healthcare System, Ann Arbor, MI, USA 
It is not difficult to make microbes resistant to penicillin ... The time may come when penicillin can be bought by anyone in the shops. Then there is the danger that the ignorant man may easily under dose himself and by exposing his microbes to non-lethal quantities of the drug make them resistant.

-Alexander Fleming's Nobel Prize

Acceptance Lecture, 1945

\section{Introduction}

The discovery of penicillin in 1928 , followed by its commercialization in the $1940 \mathrm{~s}$, ushered in the antibiotic era of medicine [1]. During that time, unparalleled advances in health care were achieved, largely through a new-found capacity to eradicate infections associated with disease states that had previously rendered their treatment unthinkable. Nevertheless, excessive use of antibiotics in the ensuing decades, coupled with underinvestment in discovery and development of new agents, has culminated in a crisis of antibiotic resistance [2], which, if left unchecked, will have catastrophic consequences for patients and the economy [3]. In response, specialty societies [4] and governmental authorities [5, 6] have advocated for a substantial increase in antibiotic stewardship activity across the health care continuum. To date, efforts to implement these antibiotic stewardship programmes (ASPs)—which are defined as coordinated efforts to optimize patient outcomes and reduce the emergence and spread of antibiotic resistance through promotion of appropriate antibiotic use-have focused on the hospital setting. However, as is described below, the need for similar efforts in nursing homes (including the care of short-stay residents with skilled nursing and rehabilitation needs, as well as long-stay residents) may be even greater. Fortunately, a considerable number of studies focused on improving antibiotic prescribing in nursing homes have been published in recent years. Consequently, the primary aims of this paper are to review the current literature on antibiotic stewardship in nursing homes and provide recommendations that facilities can implement in order to improve existing antibiotic prescribing patterns.

\section{The Need for Antibiotic Stewardship in Nursing Homes}

While the numbers vary by country, approximately $2-5 \%$ of the developed world's older population resides in some type of long-term care facility [7, 8]. For example, nearly 1.4 million persons reside in the 15,700 nursing homes in the USA [9]. Similar proportions of the populations in Canada [10] and the UK [11] reside in this type of facility. Residents in these facilities are predominantly frail and prone to developing infections. In fact, infections are the most common cause of transfers to acute care and a major source of nursing home resident morbidity and mortality [12, 13]. Against this backdrop, it is not surprising that antibiotics are among the most commonly prescribed medications in nursing homes [14]. On average, one in ten nursing home residents is receiving antibiotics on any given day [15-17]. For the resident who remains in a nursing home for at least 6 months, this translates into a $40-70 \%$ likelihood of exposure to at least one course of antibiotics [14, 18].

While antibiotics are undoubtedly beneficial in many situations, they are not uniformly benign or helpful. Antibiotics pose a risk of adverse side effects similar to that seen with antipsychotic medications [19] and account for nearly $20 \%$ of the adverse drug events observed in nursing homes [20]. A resident's risk of developing Clostridium difficile infection (CDI), an increasingly common problem encountered in nursing homes [21, 22], is amplified eightfold following treatment of a suspected urinary tract infection (UTI) [23]. Antibiotics also substantially increase a resident's risk of acquiring antibiotic-resistant bacteria [24], which may result in subsequent infections that are more expensive to treat [25] and are more likely to produce adverse health outcomes [26-28]. Residents who become colonized with antibiotic-resistant bacteria following exposure to antibiotics may also spread these organisms to other residents in the nursing home [29-32] and to individuals in other health care settings during care transitions [33]. It is increasingly clear that a substantial number of these resident harms could be avoided through improvements in antibiotic prescribing practices in nursing homes.

Prospective studies have shown that nearly half of the antibiotic courses prescribed in nursing homes are unnecessary [18, 23, 34-37]. Even when clinically indicated, the antibiotic prescribed very often is excessively broad spectrum or is continued for a duration well beyond what is required to eradicate the infection. Fluoroquinolones are the most commonly prescribed class of antibiotics in US and Canadian nursing homes, accounting for 38 and $23 \%$ of total antibiotic use, respectively [14, 17]. However, most of the infections encountered in nursing homes can be treated with alternative agents that pose lesser risks of side effects and CDI [23, 35]. Despite a number of studies demonstrating the safety and benefits of short-course antibiotic therapy [38-40], more than $60 \%$ of the residents treated for nursing home infections receive antibiotics for more than a week and nearly a third are treated for more than 10 days [17]. 


\section{The Antibiotic Prescribing Process}

Progress towards improving antibiotic prescribing practices in nursing homes requires an understanding of the decisionmaking involved. Antibiotic prescribing is best viewed as a process rather than a discrete event (Fig. 1) [41]. Conceptually, this process begins with a decision to initiate an antibiotic, as well as a related decision about which antibiotic(s) to prescribe. The initial decision to prescribe is influenced by a number of factors (Fig. 2) [42-46], although the relative influences of these factors vary not only from case to case but also depending on the country. For example, family preferences exert a considerable influence over prescriber decision-making in US, Canadian and Australian nursing homes [42, 43, 45, 47] but appear to minimally impact prescribing decisions in Dutch nursing homes [44].

In many nursing homes, the initial decision to prescribe an antibiotic is made off-site by telephone and, therefore, is heavily influenced by nursing home staff and inter-professional communication [42, 43, 47]. Decisions are often based on limited laboratory and clinical information, so clinicians frequently prescribe broad-spectrum agents to enhance coverage for a range of potential pathogens [45, 46]. Ideally, these same clinicians should then reassess the patient several days later to decide if the empirical antibiotic regimen can be de-escalated (Fig. 1). Consistent application of post-prescribing review and de-escalation, which is sometimes referred to as an 'antibiotic timeout' [48], allows the clinician to maximize the benefits of antibiotics while minimizing their adverse effects [49]. This antibiotic timeout should involve review of accumulated laboratory and imaging studies, as well as a re-evaluation of the patient's status since initiating the antibiotic. If the data suggest a non-infectious cause for the patient's illness, the antibiotic should be stopped. Conversely, if these data point towards infection, then clinicians should use the available culture results and observed changes in the patient's clinical status to select a definitive antibiotic regimen that possesses the narrowest possible spectrum and is given for the shortest possible duration.

\section{Barriers to Improving Antibiotic Use in Nursing Homes}

The underlying frailty of most nursing home residents engenders a high level of risk aversion among providers who deliver care in the nursing home setting [46]. Immunosenescence and multimorbidity, both of which increase a resident's risk of infection, are the norm in nursing homes [50, 51]. Reduced skin integrity and exposure to invasive medical devices, such as indwelling urinary catheters and feeding tubes, further compromise intrinsic host immunity [52-54]. Even when infection is identified and treated promptly, a resident's risk of experiencing adverse outcomes, such as hospitalization and death, remains high.

Diagnosis of infection in aging populations remains a challenge. Among older adults, temperature elevation (or decline/depression) in response to infection is often blunted. Cognitive impairment, which afflicts $>50 \%$ of nursing home residents, makes it difficult for residents to vocalize and/or localize their symptoms [55-59]. While nursing homes have the capacity to perform common laboratory tests, most rely upon off-site facilities for this service. Consequently, even basic laboratory test results tend to be reported a day or more after they are ordered, and culture results take even longer. Moreover, while most nursing homes have access to mobile radiographic services, the image quality may be suboptimal [60].

The unique structure of resident evaluation and treatment in nursing homes may represent the most important barrier to improving antibiotic stewardship. While an increasing number of providers in the USA and some other countries practice primarily in the nursing home setting [61, 62], the majority of care in nursing homes is delivered by providers who, on average, physically spend less than $2 \mathrm{~h}$ per week in a nursing home [63, 64]. Consequently, most antibiotic decisions are made by off-site providers during brief telephone interactions with facility nursing staff $[65,66]$. This process relies heavily on certified nursing assistants (CNAs) and licensed nursing staff. A CNA is frequently the first individual to recognize a
Fig. 1 Components of the antibiotic prescribing decisionmaking process

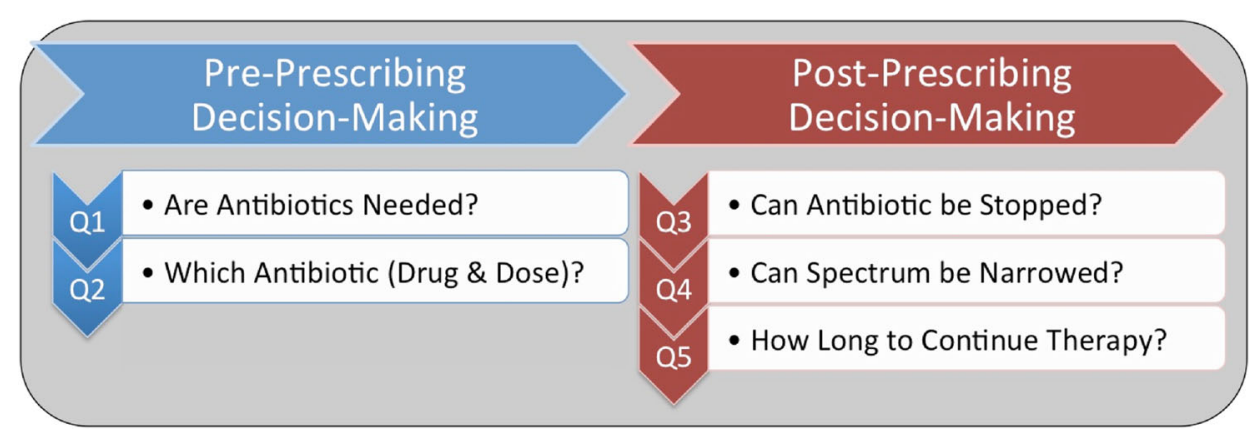


Fig. 2 Conceptual framework of the factors that influence the decision to initiate antibiotic therapy in nursing homes

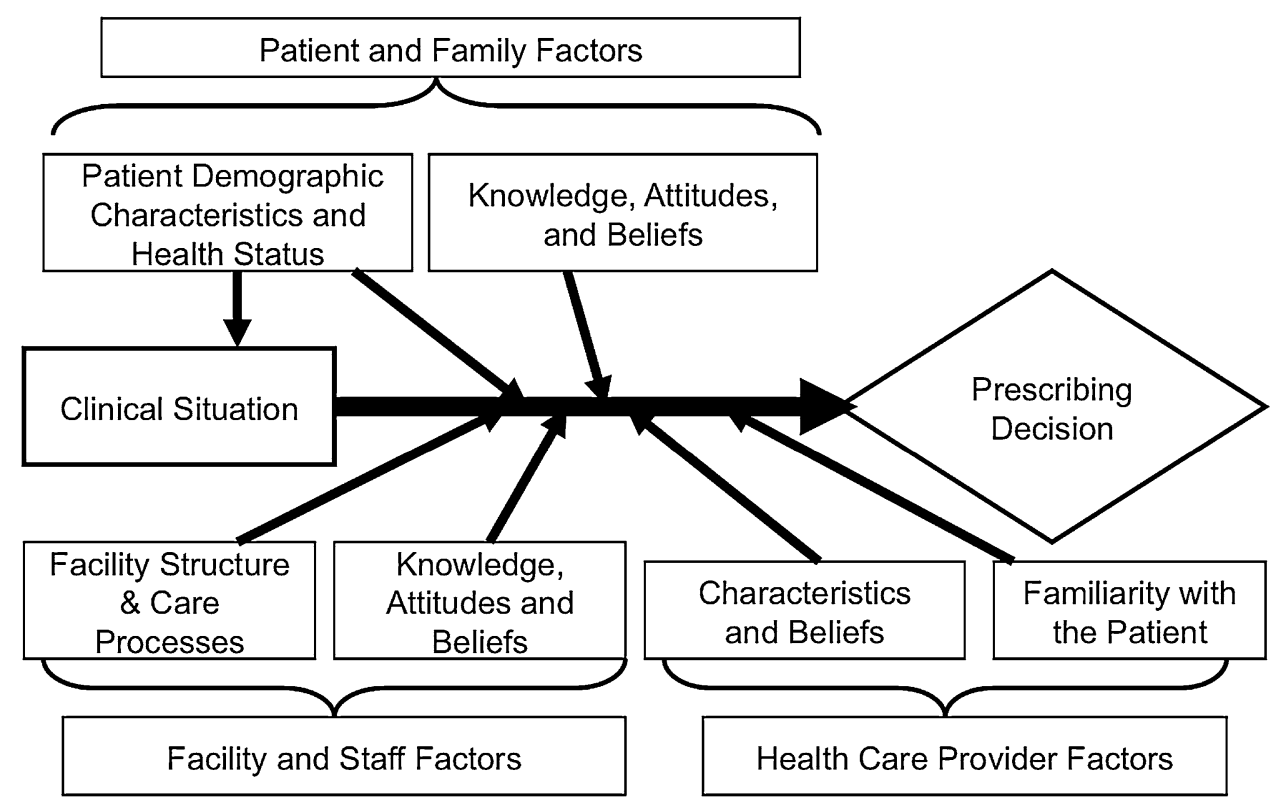

resident's change in condition and can play a critical role in assisting nursing staff in evaluation of the resident. However, resources devoted to the training of these individuals is often minimal, and retention of experienced individuals continues to be a challenge for many nursing homes [67, 68]. Accordingly, a registered nurse (RN) or licensed practical nurse (LPN) must not only complete the initial assessment and examination of a resident with a change in condition but also communicate those findings to the provider on call. The nurses' workload and familiarity with the residents influence this process. Unfortunately, nurse-toresident ratios [69] and consistent assignments remain suboptimal in many nursing homes [70]. Moreover, a high reliance on agency staff [69], as well as high levels of staff turnover [71], further compound the problem. It is, therefore, not surprising that providers often express frustration over the quality of information received during their telephone interactions with nursing home staff [72-74]. The clinical uncertainty engendered by these assessment and communication processes may, in part, lower the threshold at which providers decide to prescribe an antibiotic [75, 76].

\section{Existing Studies of Antibiotic Stewardship in Nursing Homes}

A loose definition of antibiotic stewardship encompassing interventions to alter antibiotic prescribing patterns in nursing homes, including decisions to initiate antibiotic therapy, as well as the choice and duration of therapy, was employed in the development of this review. A formal systematic review process was not employed in the identification and quality assessment of the studies considered in this review. However, the lead author (CJC) did conduct a search of PubMed articles available as of April 2015, reviewed citation lists from the retrieved review articles [77-79] and further reviewed abstracts and presentations at pertinent international scientific meetings (e.g. IDWeek) in order to identify potential studies for review. Co-authors contributed to the identification of additional articles not identified by this initial retrieval process and also participated in the interpretation of individual study findings, which were then synthesized through group consensus. This process led to the identification of 14 studies focused on altering antibiotic prescribing practices in nursing homes (Table 1). Most of the interventions described in these studies focused on empirical prescribing decisionmaking through interventions to either reduce initiation of unnecessary antibiotics (Q1 in Fig. 1) [80-87] or enhance adherence to antibiotic prescribing guidelines (Q2 in Fig. 1) [81, 83, 88-91]. The impacts of these interventions on measured outcomes varied considerably across studies. Nevertheless, review of the studies in aggregate points to several promising strategies.

\subsection{UTI-Focused Interventions}

The most common indication for initiation of antibiotics in nursing homes is UTI [14, 36, 92, 93]. Nevertheless, most residents treated for UTI do not manifest symptoms that are localized to the urinary tract [56]. Rather, studies suggest that a substantial number of these events represent unnecessary treatment of asymptomatic bacteriuria [58, 94]. 
Vague symptoms that have no clear relationship to the urinary tract, such as malaise or falls, are often cited as a reason to test resident urine samples [56]. Unfortunately, urine diagnostic tests-including the rapid urine reagent strip (dipstick), urinalysis and urine culture-fail to discriminate between UTI and asymptomatic bacteriuria [9597]. Nonetheless, there is compelling evidence that positive urine test results play an inordinate role in the decision to initiate an antibiotic [94]. For example, 60-90\% of the antibiotics prescribed for UTI in nursing homes are initiated only after urine cultures results are available [56, 98]. Moreover, withholding urine culture results, unless specifically requested by the provider, substantially reduces the frequency of antibiotic starts in hospitals without adversely affecting patient outcomes [99].

On the basis of these observations, it is reasonable to hypothesize that antibiotic prescribing for UTI can be reduced through interventions that target over-testing of resident urine samples. The first large-scale study to test this hypothesis employed criterion-based pathways to limit urinary testing and antibiotic prescribing to residents with fever and/or localizing urinary symptoms [80]. This study, performed in 24 nursing homes in the USA and Canada, demonstrated a reduction in antibiotic prescribing for UTI (1.17 versus 1.59 antibiotic starts per 1000 resident-days), but the effects waned over time, and there was a nonsignificant impact on orders for urine cultures (2.03 versus 2.48 cultures per 1000 resident-days), suggesting issues with intervention sustainability and fidelity [100]. Nevertheless, a subsequent study in a single Veterans Affairs (VA) nursing home demonstrated an impressive reduction in urine cultures (1.5 versus 3.7 cultures per 1000 residentdays), treatment of asymptomatic bacteriuria (0.6 versus 1.7 courses per 1000 resident-days) and overall days of antibiotic therapy (117 versus 168 days per 1000 residentdays) following implementation of the same intervention [82]. Similarly, treatment of asymptomatic bacteriuria was reduced from 52 to $10 \%(P=0.001)$ following implementation of a cognitive intervention [101] focused on limiting urine cultures in residents with guideline discordant symptoms (e.g. foul-smelling urine) [87]. Finally, significant reductions in urine cultures [incidence rate ratio (IRR) 0.73 ; $95 \%$ confidence interval (CI) 0.66 to 0.79 ] and antibiotic therapy for UTI (IRR 0.67; $95 \% \mathrm{CI}$ 0.59-0.76) were achieved following implementation of a quality improvement collaborative focused on improving urine testing in 17 Massachusetts nursing homes [86].

\subsection{Standardized Assessment and Communication Interventions}

Despite the availability of guidelines [102], there is evidence that assessments of residents with possible infection are suboptimal in many nursing homes [18, 34, 65]. Even when the assessment is thorough, the quality of the communication between facility nursing staff and providers, which has been previously linked to use of antipsychotics [103] and avoidable hospitalizations [73, 104], may be suboptimal. While the linkage between communication and antibiotic prescribing is less clear [42], interventions structured around standardizing resident assessments and interdisciplinary communication have led to reductions in antibiotic use in nursing homes [84, 85]. A medical provider and nurse-based intervention-which included training on antibiotic stewardship, a simple form that facilitated standardization of communication with providers and an informational brochure for families and residents-led to lower overall antibiotic prescribing in comparison with control facilities (IRR 0.86; $95 \% \mathrm{CI}$ 0.79-0.95) [85]. Similarly, antibiotic prescribing in Texas nursing homes was $33 \%$ lower in nursing homes that implemented a standardized communication and UTI decision-support form with high fidelity in comparison with control nursing homes and facilities that implemented the form with low fidelity [84].

\subsection{Educational Interventions}

Education can be an effective behavioural intervention in situations where knowledge deficiencies drive observed practice patterns [105]. The available studies suggest that educational interventions have a modest impact on antibiotic use in nursing homes. The number of antibiotic starts dropped by $26 \%$ and days of antibiotic therapy were reduced by $30 \%$ following implementation of a case-based educational intervention focused on treatment of commonly encountered infections in a Chicago long-term care facility [81]. The impact of educational interventions when delivered across multiple facility settings has been less impressive. A cluster-randomized study of an educational intervention to improve adherence to a prescribing guideline in Canadian nursing homes demonstrated improvements in provider guideline adherence rates, but this difference did not remain significant during long-term follow-up [89]. Similarly, a cluster-randomized study of an educational intervention to reduce fluoroquinolone utilization in Swedish nursing homes did not demonstrate a significant impact on this particular prescribing pattern, although the proportion of infections treated with antibiotics was lower in intervention nursing homes compared with control facilities (difference-in-differences of proportions $-0.124 ; 95 \% \mathrm{CI}-0.228$ to -0.019 ) [83]. Interestingly, the effectiveness of educational interventions may rely on simultaneous delivery of content to facility nursing staff and prescribing providers. A cluster-randomized trial of an educational intervention to improve antibiotic 


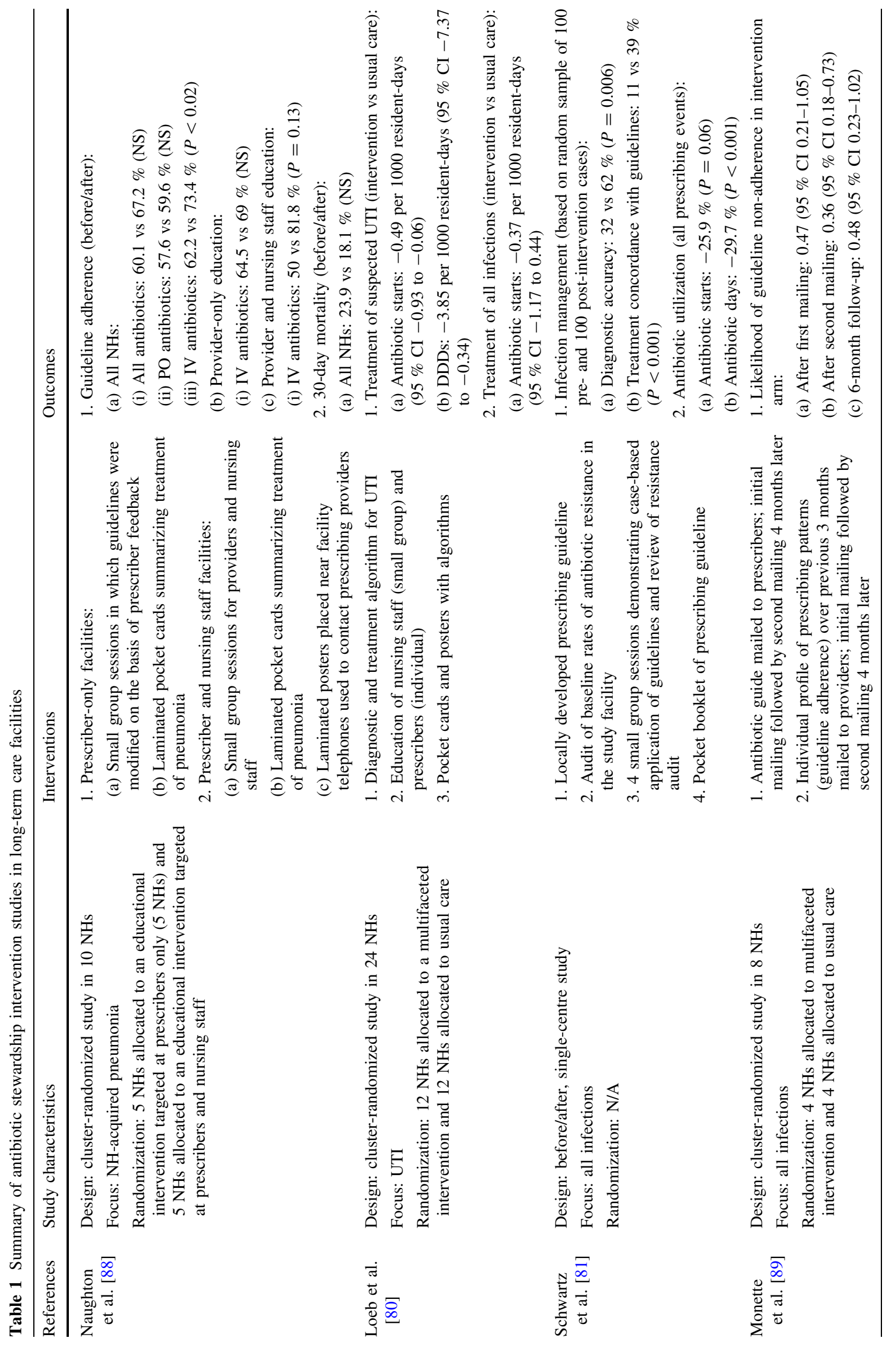




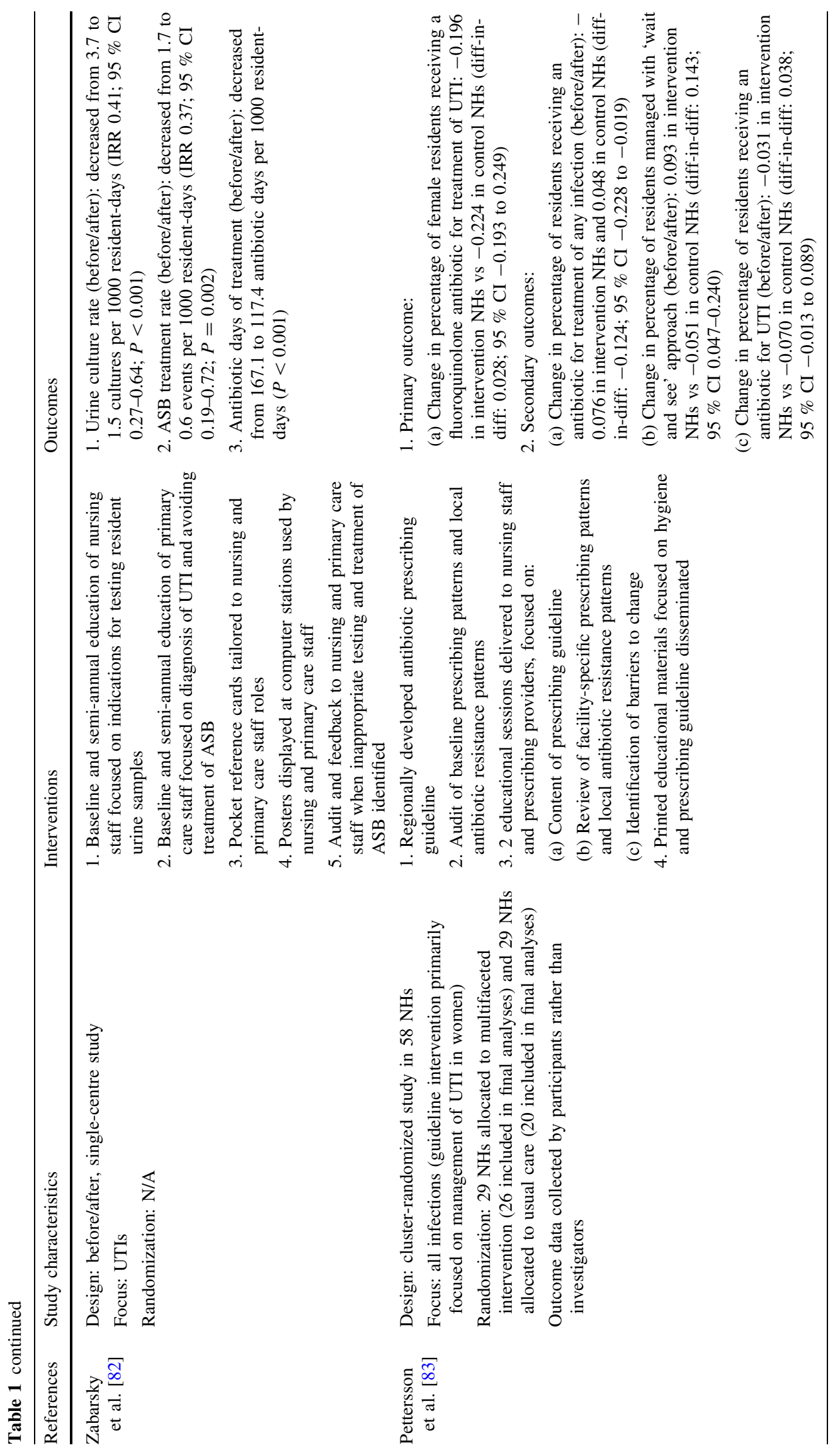




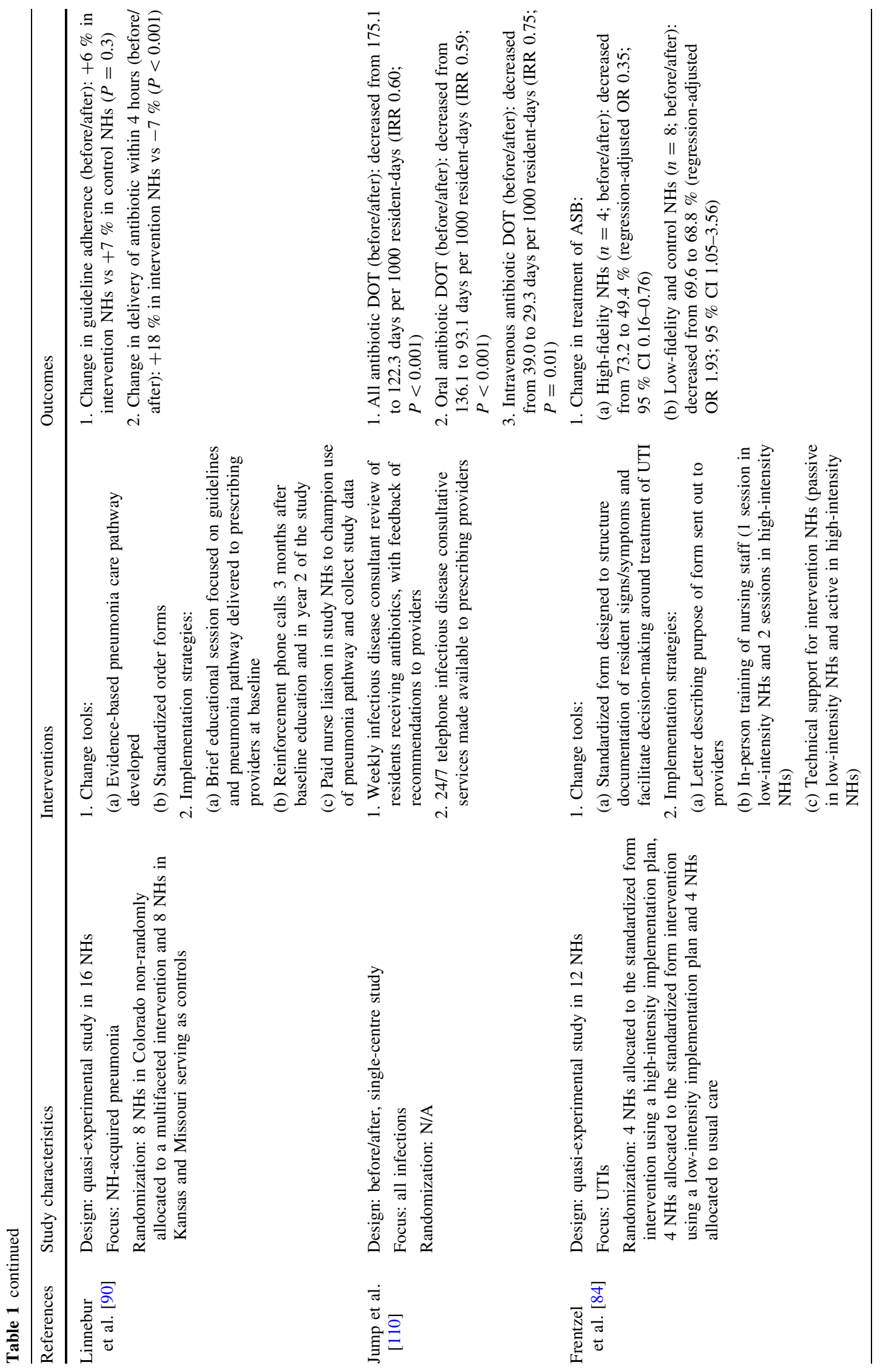




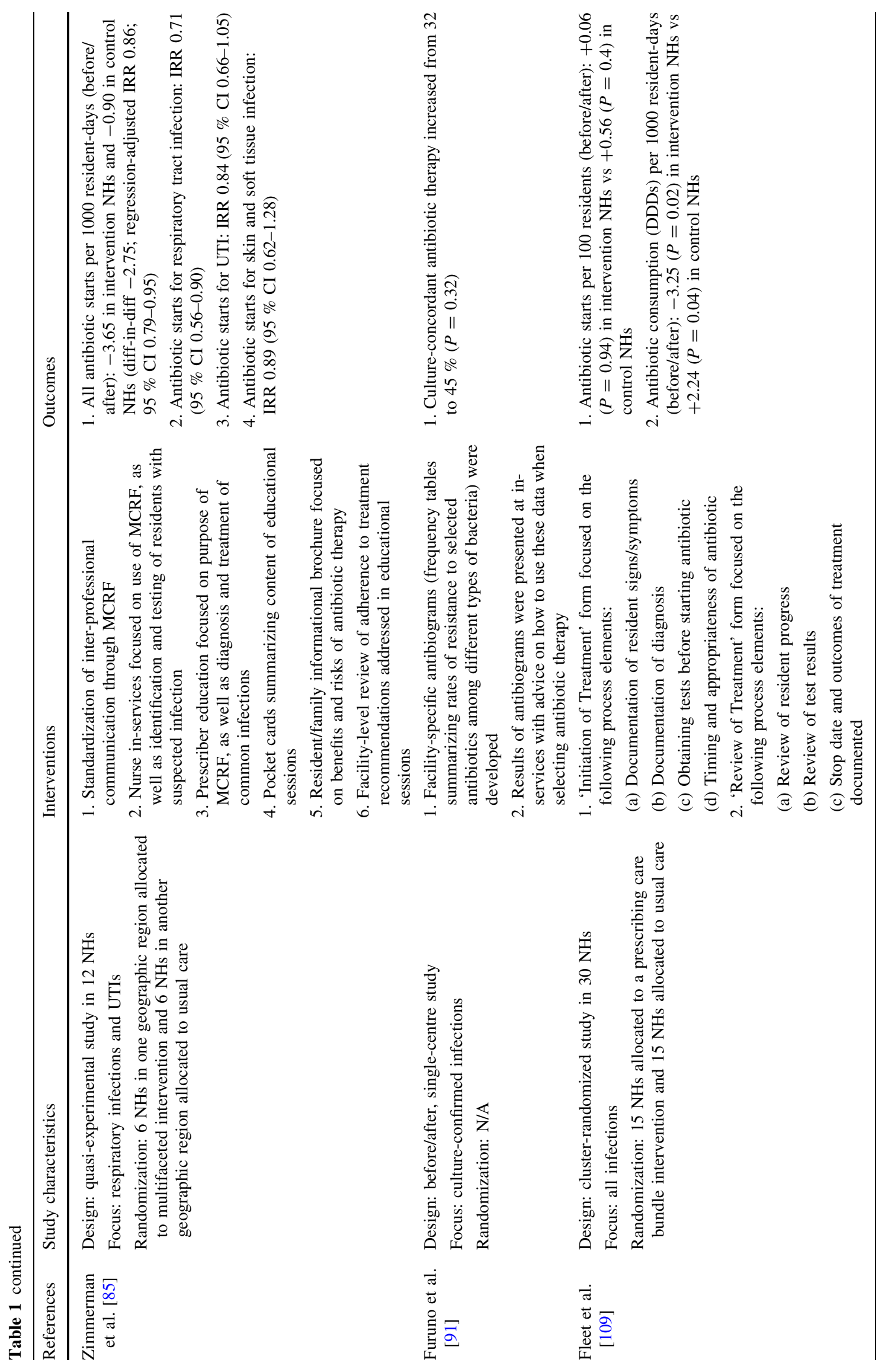




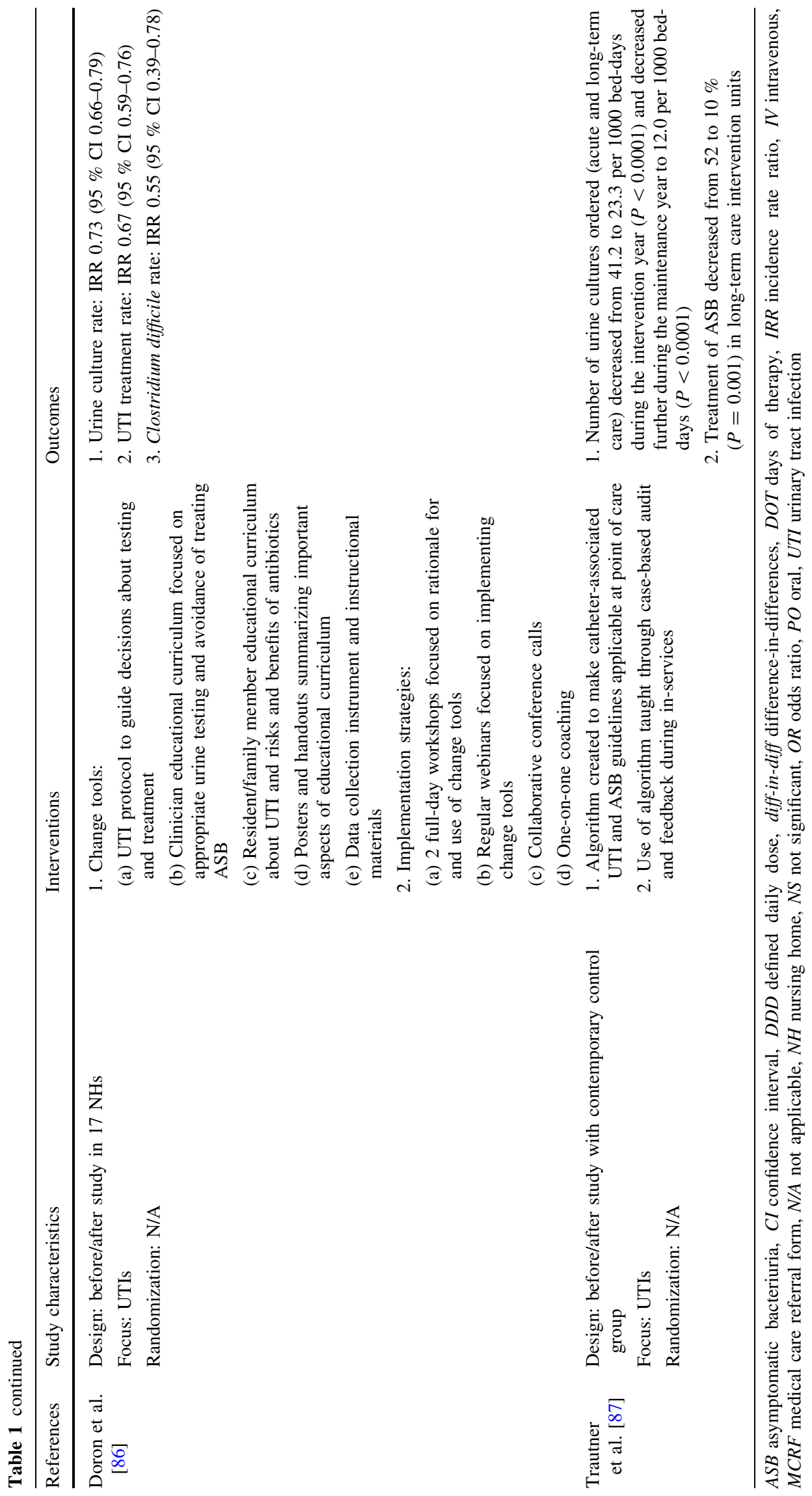


prescribing for pneumonia in New York nursing homes demonstrated a significant improvement in adherence to prescribing guidelines (from 50 to $82 \%$ ) in facilities where education was targeted at both types of clinical staff [88]. In contrast, guideline adherence remained essentially unchanged (69 versus $65 \%$ ) in nursing homes where education was targeted solely at prescribing providers [88].

\subsection{De-Escalation Interventions}

Post-prescribing review and de-escalation interventions (Q3-5 in Fig. 1) have had a profound impact on antibiotic utilization in hospitals [106]. Not surprisingly, there is evidence that de-escalation interventions have the potential for similar impact in nursing homes. Fluoroquinolones are among the most commonly prescribed antibiotics in US nursing homes [14]; however, studies have shown that providers rarely switch to agents with a more narrow spectrum (e.g. trimethoprim-sulfamethoxazole) even when culture results indicate a fully susceptible pathogen [23]. Moreover, a large observational study of nursing homes in Ontario demonstrated that the majority of antibiotic prescriptions exceeded durations of therapy sufficient for treatment of the most commonly encountered infections [17]. A follow-up study by these investigators confirmed that only a minority of prescribers $(22 \%)$ employed shortcourse therapy accepted in most guidelines [107]. Convincing providers who typically prescribed antibiotics for longer durations to prescribe antibiotics in a similar manner would reduce the total number of antibiotic days in Canadian nursing homes by $17 \%$ [107]. A recently published study of 100 prescribing events in a VA nursing home demonstrated that $43 \%$ of 1351 antibiotic days associated with these events could have been safely eliminated either by stopping the antibiotic because it was unnecessary or by shortening the duration of therapy [108].

Despite these opportunities, antibiotic de-escalation interventions remain poorly studied in the nursing home setting. A cluster-randomized study of a multi-component intervention, which included a routine post-prescribing review of empirically initiated antibiotics in 30 nursing homes in London, demonstrated a $5 \%$ reduction in antibiotic consumption in intervention facilities compared with control facilities despite low adherence to the post-review procedures (26\%) [109]. Another study examined the impact of an infectious disease consultative service, which involved remote consultation services during daytime hours, as well as once-weekly in-person resident assessments, on antibiotic prescribing and resident outcomes in a 160-bed VA nursing home [110]. Significant declines in systemic antibiotic use $(-30 \% ; P<0.001)$ and facility rates of $C$. difficile (slope $0.03 ; P=0.04)$ were observed over the 18 -month intervention period in this study.

\section{Suggested Approach to Antibiotic Stewardship in Nursing Homes}

While there are many barriers to be overcome, the available data do suggest that antibiotic prescribing patterns in nursing homes can be improved through interventions that target different phases of the antibiotic prescribing process (Fig. 1). Combining interventions that target the different phases of the prescribing process and mitigate against influences that promote inappropriate antibiotic prescribing decisions (Fig. 2) has intrinsic appeal [85] but requires more study [111]. These technical observations aside, sustainability of any particular intervention is unlikely unless nursing homes develop a dedicated focus on improvement (Fig. 2-facility and staff factors) [112]. With this in mind, we propose that nursing homes first develop structures and processes focused on understanding local patterns, determinants and outcomes of antibiotic use (Sects. 6.1-6.4), and then leverage this infrastructure to develop staff/provider education (Sect. 6.5) and implement targeted process interventions (Sect. 6.6).

\subsection{Make Antibiotic Stewardship a Quality Improvement Focus}

Changing nursing home culture requires commitment at an organizational level. Consequently, the first step is to obtain buy-in from the facility leadership, including the director of nursing and the medical director, to make antibiotic stewardship a facility quality improvement focus. Arguments that nursing home leaders find persuasive include (1) a need to satisfy regulatory requirements focused on appropriate use of medications; (2) federal mandates to demonstrate meaningful organizational quality assurance and performance improvement (QAPI) [113]; (3) emerging federal policies to promote and ultimately require antibiotic stewardship activities across all health care settings [6]; (4) organizational costs of treating antibiotic-resistant infections and CDI [25, 114]; and (5) how certain antibiotic stewardship interventions, particularly those focused around enhancing interdisciplinary communication, can generate corollary benefits in other nursing home processes and outcomes (e.g. enhanced management of resident changes in condition).

\subsection{Assemble a Team}

Antibiotic prescribing in nursing homes is a complex problem and involves a number of factors [115]. Facilities dedicated to improving the quality of antibiotic prescribing should assemble a multidisciplinary team that, at a minimum, involves the facility medical director, the director of nursing, an infection control practitioner and, if available, 
the facility pharmacist [116]. Initial meetings should focus on identification of outcome measures that will be targeted by improvement efforts, resources that will be needed to achieve these objectives, and duties and responsibilities of team members and expectations of nursing home staff and prescribing providers as they relate to antibiotic use in the facility. Seeking input from individuals with expertise in antibiotic stewardship and infectious diseases in the region can be particularly helpful at this stage. This team should plan to meet at least monthly when first getting started.

\subsection{Develop and Implement Basic Policies, Guidelines and Goals}

Provider orders for antibiotics should include clear documentation of the drug, dose, duration and indication. This latter requirement is critical for tracking antibiotic utilization (see below). Policies should be developed that discourage the use of prophylactic antibiotics for prevention of UTI and routine urine dipstick testing when evaluating a resident experiencing a change in condition. The antibiotic stewardship team should also consider developing policies and guidelines that limit the use of fluoroquinolone antibiotics, given their strong relationship to $C$. difficile [117] and high rates of resistance among urinary pathogens in many facilities [91, 118, 119]. More detailed guidelines that specify the choice and duration of antibiotic therapy for commonly encountered syndromes can be very effective in improving prescribing quality [81] but may require substantial effort to develop.

\subsection{Measure and Report Outcomes and Key Process Indicators}

A capability to measure and track process and outcomes is a fundamental characteristic of successful quality improvement [120]. Most nursing homes routinely track commonly encountered infections [52,121]. Adapting this process to monitor, at a minimum, UTI events and CDI should not prove too difficult for most facilities. We recommend that UTI be tracked in two ways: (1) treated UTI events (i.e. all antibiotic starts regardless of whether the event was a true infection); and (2) surveillance-defined UTI events (i.e. only those events that satisfy published criteria) $[121,122]$. These measures can then be tracked in a number of ways. Point prevalence measurements (e.g. measuring the numbers of UTI events in the months before and after an intervention) are relatively easy to perform. Tracking outcomes using rates (e.g. UTI events per month/ resident-days per month $\times 1000$ ) is a more rigorous approach, which may allow a facility to more accurately assess the impact of multiple interventions over time. CDI can be tracked in a similar manner using the National
Healthcare Surveillance Network (NHSN) criteria, which consider the rate of non-duplicative positive tests per 10,000 resident-days [123]. Nursing homes may also consider including residents transferred to their facility with C. difficile in that rate [124]. Extending monitoring to other types of infections, including those involving the respiratory tract and soft tissues, should be considered, as these are the second and third most common indications for initiation of antibiotic therapy in the nursing home setting $[14,125]$. Finally, facilities should discuss developing a facility-specific antibiogram [119] in consultation with their contract laboratory. The antibiogram is a tool that facilities can use to identify common resistance patterns (e.g. high levels of fluoroquinolone resistance), which may influence providers' empirical antibiotic decisions [91]. The small number of cultures collected in nursing homes may create instability in observed patterns of resistance and should be interpreted in consultation with individuals with infectious disease expertise.

Nursing homes embarking on quality improvement in antibiotic prescribing should seek to track antibiotic use in some manner. Logistics, as well as the types of improvement interventions that will be pursued, should guide the measure(s) selected. Most nursing homes employ tracking methods to identify residents experiencing a change in condition, including those residents who are currently receiving antibiotics [126]. Consequently, information on antibiotic starts is readily available and can be tracked at predefined time periods by the individual responsible for infection surveillance in the facility. Cross-sectional assessments of antibiotic use involve counting the number of resident on antibiotics during a given day or week. These assessments are fairly simple and do not require a huge amount of effort, but they may not be as sensitive to change as measures that are tracked more regularly. Tracking antibiotic starts per month (like other continuously monitored outcomes, this measure should be converted to a rate using resident-days as a denominator) is a more involved process, which allows facilities to trend and visualize their data. These data can be further stratified by indication (antibiotic starts for UTI, respiratory tract infection, skin and soft tissue infection), particularly if the indications for the antibiotic are routinely included on prescriber orders (see above). Antibiotic start data are ideal for tracking the effects of interventions focused on reducing unnecessary antibiotic use (e.g. reducing urine cultures) but may not be very informative for interventions that focus on reducing the duration of antibiotic therapy (e.g. guidelines or de-escalation). Facilities seeking to implement interventions along these lines should seek to track antibiotic utilization using either a days of therapy (DOT) measure [127] or a defined daily dose (DDD) measure [16]. The DOT utilization measure is derived by adding up every 


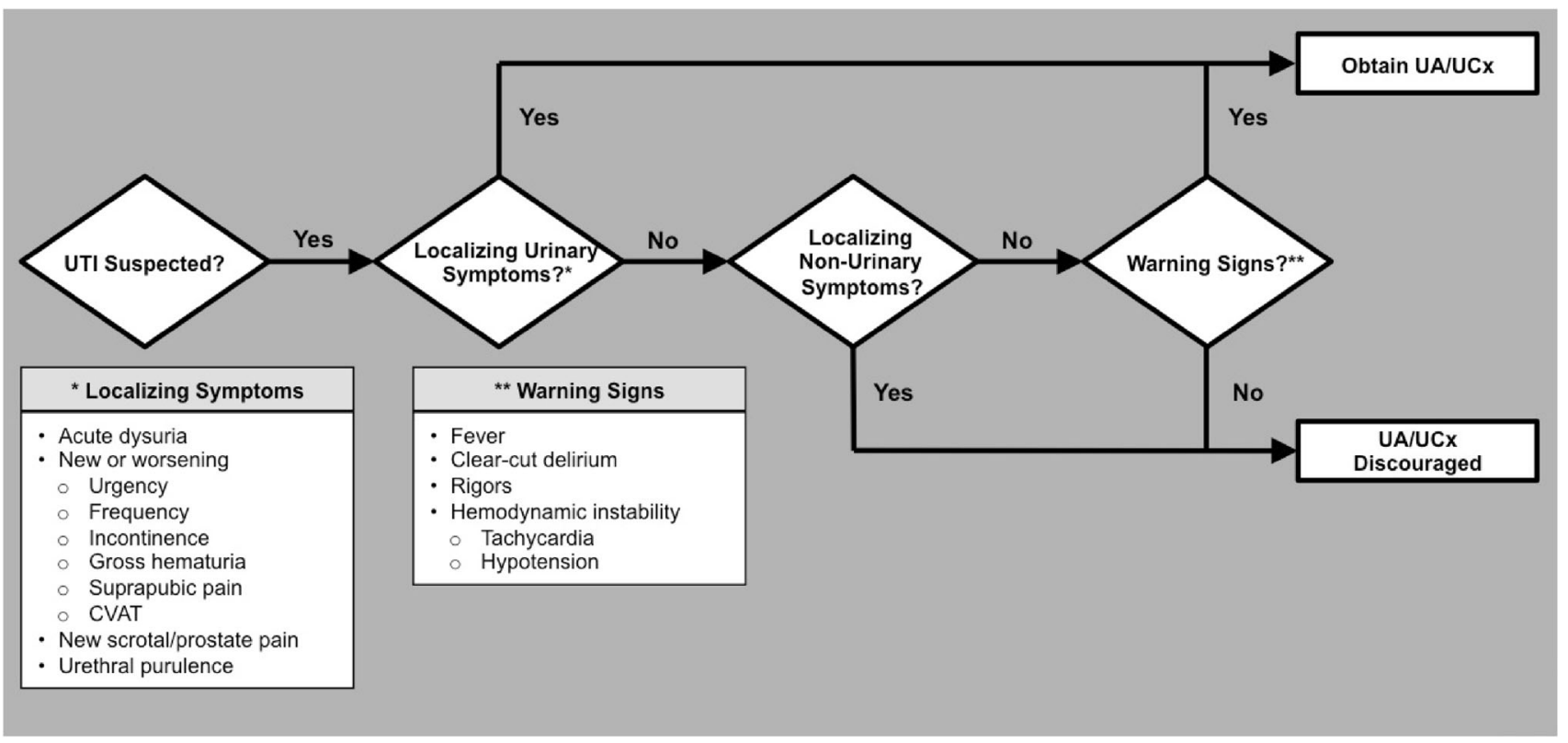

Fig. 3 Decision pathway to reduce unnecessary diagnostic testing of urine samples in long-term care facilities (adapted from Crnich and Drinka [94]). CVAT costovertebral angle tenderness, UA urinalysis, UCX urine culture, UTI urinary tract infection

day on which a resident receives a unique antibiotic. By this method, receipt of multiple antibiotics has additive effects on the measure (e.g. a resident who receives 5 days of ceftriaxone and 5 days of azithromycin would generate 10 DOT even if both antibiotics are administered on the same day). In contrast, the DDD utilization measure is based on overall consumption of a particular antibiotic adjusted for typical daily dosing in an adult patient with intact renal function. By this approach, the total number of grams of each antibiotic used (or purchased) are summed over the period of interest and divided by the World Health Organization's assigned DDD value [128]. Manual collection of these types of data poses a challenge. Consequently, working with the facility pharmacist to automate this process through queries of the pharmacy information system is recommended.

\subsection{Education}

Education is a foundational activity of any ASP and can be used to target all three domains influencing prescribing decisions in nursing homes (Fig. 2-patient and family factors, facility and staff factors, health care provider factors). Educational content should cover the importance of stewardship, plans for implementation of specific stewardship activities and the responsibilities of clinical staff in achieving stewardship goals. Education should be targeted and tailored to nursing assistants, nursing staff, providers, residents and families. While not focused on antibiotic prescribing practices, a recently published study performed in 12 Michigan nursing homes demonstrated that a multimodal educational intervention focused on common infection prevention practices and care processes associated with indwelling urinary catheters and feeding tubes was associated with significant reductions in rates of MRSA acquisition [absolute risk reduction (ARR) 0.78; $95 \%$ CI 0.65-0.95] and catheter-associated UTI (ARR 0.69; $95 \%$ CI 0.49-0.99) [129]. Resident and family education, when combined with staff and provider education, as well as interventions to enhance interdisciplinary communication, has also recently been shown to be associated with reductions in antibiotic use in nursing homes [85]. Studies such as these demonstrate that educational interventions can be powerful tools for changing behaviours but likely need to target multiple individuals [88] and be delivered via a number of modalities-including in-service training sessions, newsletters, pocket guides, posters and brochures-in order to be maximally effective.

\subsection{Next Steps}

Once a facility has established its basic policies, outcome and process measures and has developed basic educational activities, the stewardship team should use the collected data to set new goals and select more active strategies in order to achieve these goals. As noted above, antibiotic decision-making in nursing homes is heavily influenced by 
diagnostic test results, and we believe that facilities will see the biggest return on investment through a focus on implementing interventions to reduce orders for urine cultures. Urine dipstick and urinalysis tests, despite being reliable methods for ruling out bacteriuria [130, 131], are often used to justify orders for urine cultures. Mild abnormalities on urinalysis, such as positive nitrite or leukocyte esterase readings on dipsticks, or moderate numbers of white blood cells on microscopy, are common in asymptomatic bacteriuria [96, 97], so neither test should be used as a screen for UTI. Consequently, nursing homes should instead develop and use protocols that restrict all urine testing to residents with a high probability of having a UTI (Fig. 3). These protocols should be operationalized not only through education of providers but, given their influence on provider decision-making [42, 43], also through engagement of nursing staff, who should be empowered to discourage providers from ordering diagnostic urine tests in the absence of specific evidence-based criteria. Tracking the frequency of urine cultures and the number of treated UTI events that do not satisfy surveillance definitions [121] provides targets that a facility can follow in order to assess the impact of the intervention. Other approaches based on improving interdisciplinary communication through tools that standardize documentation and sharing of important patient information, as well as development of a process to ensure consistent post-prescribing review and de-escalation, may represent a greater challenge but are worth considering, particularly if success in reducing the frequency of urine cultures has been achieved.

\section{Unanswered Questions and Future Directions}

The emerging crisis in antibiotic resistance will require a concerted effort to improve antibiotic stewardship across all health care settings [6]. Considerable progress has been made in our understanding of the extent and determinants of inappropriate antibiotic use in nursing homes. While there is accumulating evidence that interventions focused on processes (e.g. urine testing) associated with the initial antibiotic decision can reduce unnecessary antibiotic use, there remains a critical need to identify interventions that target post-prescribing decision-making (e.g. review and de-escalation). There is also a need for more research on how to implement both types of stewardship interventions with fidelity and sustain them over time, particularly in nursing homes with limited quality improvement resources. Finally, there is a need for studies that evaluate the effects of stewardship interventions on facility and resident outcomes, including health care costs, as well as rates of infections caused by $C$. difficile and multidrug-resistant bacteria.
Acknowledgments Christopher Crnich is funded by grants from the Agency for Healthcare Research and Quality (AHRQ; Nos. R18HS022465 and HHSA290201000018I) and the State of Wisconsin Department of Health Services. Robin Jump's research is supported, in part, by the Cleveland VA Geriatric Research Education and Clinical Center (GRECC) and by grants from the Atlantic Philanthropies and John A. Hartford Foundation (T. Franklin Williams Scholarship) and the Clinical and Translational Science Collaborative of Cleveland [No. UL1TR000439; National Institutes of Health (NIH)-National Center for Advancing Translational Sciences (NCATS)]. Barbara Trautner's research is supported, in part, by the Houston VA Center for Innovations in Quality, Effectiveness and Safety (CIN13-413) and by a grant from the AHRQ (No. HHSA2902010000251). Philip Sloane's work is funded by grants from the AHRQ (Nos. R18HS022846 and R01HS22298) and NIH (Nos. R01AG042602, R01NR014199 and R41NR015200). Lona Mody's research is supported, in part, by the University of Michigan Claude D. Pepper Older American Independence Center and by grants from the NIH (Nos. R01AG032298 and R01AG041780), National Institute of Aging (NIA)and AHRQ (No. R18HS019979). None of the authors have potential conflicts of interests that are directly relevant to the content of this review.

Open Access This article is distributed under the terms of the Creative Commons Attribution-NonCommercial 4.0 International License (http://creativecommons.org/licenses/by-nc/4.0/), which permits any noncommercial use, distribution, and reproduction in any medium, provided you give appropriate credit to the original author(s) and the source, provide a link to the Creative Commons license, and indicate if changes were made.

\section{References}

1. Aminov RI. A brief history of the antibiotic era: lessons learned and challenges for the future. Front Microbiol. 2010;1:134.

2. Spellberg B, Guidos R, Gilbert D, Bradley J, Boucher HW, Scheld WM, et al. The epidemic of antibiotic-resistant infections: a call to action for the medical community from the Infectious Diseases Society of America. Clin Infect Dis. 2008;46:155-64.

3. O'Neill J. Antimicrobial resistance: tackling a crisis for the health and wealth of nations [Internet]. The review on antimicrobial resistance; 2014. Available from: http://amr-review.org/ sites/default/files/AMR\%20Review\%20Paper\%20-\%20Tackling $\% 20$ a $\% 20$ crisis $\% 20$ for $\% 20$ the $\% 20$ health $\% 20$ and $\% 20$ wealth $\%$ 20of\%20nations_1.pdf. Accessed 7 Feb 2015.

4. Society for Healthcare Epidemiology of America. Infectious Diseases Society of America, Pediatric Infectious Diseases Society. Policy statement on antimicrobial stewardship. Infect Control Hosp Epidemiol. 2012;33:322-7.

5. Pollack LA, Srinivasan A. Core elements of hospital antibiotic stewardship programs from the Centers for Disease Control and Prevention. Clin Infect Dis. 2014;59(Suppl 3):S97-100.

6. The White House. National strategy for combatting antibiotic resistant bacteria. 2014 [Internet]. 2014. Available from: http:// www.whitehouse.gov/sites/default/files/docs/carb_national_ strategy.pdf. Accessed 17 Mar 2015.

7. Ribbe MW, Ljunggren G, Steel K, Topinková E, Hawes C, Ikegami $\mathrm{N}$, et al. Nursing homes in 10 nations: a comparison between countries and settings. Age Ageing. 1997;26(Suppl 2):3-12.

8. European Social Network. Services for older people in Europe: facts and figures about long term care services in Europe 
[Internet]. 2008. Available from: http://ec.europa.eu/health/mental_ health/docs/services_older.pdf.

9. Harris-Kojetin LD, Sengupta M, Park-Lee E, Valverde E. Longterm care services in the United States: 2013 overview. National health care statistics report; no. 1. Hyattsville: National Center for Health Statistics; 2013.

10. Statistics Canada. Residential care facilities 2009/2010 (catalogue no. 83-237-X) [Internet]. 2011. Available from: http://www. statcan.gc.ca/pub/83-237-x/83-237-x2012001-eng.pdf. Accessed 1 July 2015.

11. Boyle S. United Kingdom (England): health system review. Health Systems in Transition [Internet]. 2011;13:1-486. Available from: http://www.euro.who.int/_data/assets/pdf_file/0004/ 135148/e94836.pdf. Accessed 1 July 2015.

12. Strausbaugh LJ, Joseph CL. The burden of infection in longterm care. Infect Control Hosp Epidemiol. 2000;21:674-9.

13. Richards C. Infections in residents of long-term care facilities: an agenda for research. Report of an expert panel. J Am Geriatr Soc. 2002;50:570-6.

14. Benoit S, Nsa W, Richards C, Bratzler D, Shefer A, Steele L, et al. Factors associated with antimicrobial use in nursing homes: a multilevel model. J Am Geriatr Soc. 2008;56:2039-44.

15. Pakyz AL, Dwyer LL. Prevalence of antimicrobial use among United States nursing home residents: results from a national survey. Infect Control Hosp Epidemiol. 2010;31:661-2.

16. McClean P, Hughes C, Tunney M, Goossens H, Jans B. European Surveillance of Antimicrobial Consumption (ESAC) Nursing Home Project Group. Antimicrobial prescribing in European nursing homes. J Antimicrob Chemother. 2011;66: 1609-16.

17. Daneman N, Gruneir A, Newman A, Fischer HD, Bronskill SE, Rochon PA, et al. Antibiotic use in long-term care facilities. J Antimicrob Chemother. 2011;66(12):2856-63.

18. Warren JW, Palumbo FB, Fitterman L, Speedie SM. Incidence and characteristics of antibiotic use in aged nursing home patients. J Am Geriatr Soc. 1991;39:963-72.

19. Field TS, Gurwitz JH, Avorn J, McCormick D, Jain S, Eckler M, et al. Risk factors for adverse drug events among nursing home residents. Arch Intern Med. 2001;161:1629-34.

20. Gurwitz JH, Field TS, Avorn J, McCormick D, Jain S, Eckler M, et al. Incidence and preventability of adverse drug events in nursing homes. Am J Med. 2000;109:87-94.

21. Crnich CJ, Safdar N, Robinson J, Zimmerman D. Longitudinal trends in antibiotic resistance in US nursing homes, 2000-2004. Infect Control Hosp Epidemiol. 2007;28:1006-8.

22. Campbell RJ, Giljahn L, Machesky K, Cibulskas-White K, Lane LM, Porter K, et al. Clostridium difficile infection in Ohio hospitals and nursing homes during 2006. Infect Control Hosp Epidemiol. 2009;30:526-33.

23. Rotjanapan P, Dosa D, Thomas KS. Potentially inappropriate treatment of urinary tract infections in two Rhode Island nursing homes. Arch Intern Med. 2011;171:438-43.

24. Drinka PJ, Crnich CJ, Nace DA. An antibiotic prescription induces resistance at the individual level more than the group level. J Am Med Dir Assoc. 2013;14:707-8.

25. Capitano B, Leshem O, Nightingale C, Nicolau D. Cost effect of managing methicillin-resistant Staphylococcus aureus in a longterm care facility. J Am Geriatr Soc. 2003;51:10-6.

26. Carmeli Y, Troillet N, Karchmer AW, Samore MH. Health and economic outcomes of antibiotic resistance in Pseudomonas aeruginosa. Arch Intern Med. 1999;159:1127-32.

27. Lautenbach E, Strom BL, Bilker WB, Patel JB, Edelstein PH, Fishman NO. Epidemiological investigation of fluoroquinolone resistance in infections due to extended-spectrum beta-lactamase-producing Escherichia coli and Klebsiella pneumoniae. Clin Infect Dis. 2001;33:1288-94.
28. Cosgrove SE, Sakoulas G, Perencevich EN, Schwaber MJ, Karchmer AW, Carmeli Y. Comparison of mortality associated with methicillin-resistant and methicillin-susceptible Staphylococcus aureus bacteremia: a meta-analysis. Clin Infect Dis. 2003;36:53-9.

29. O'Fallon E, Kandell R, Schreiber R, D'Agata E. Acquisition of multidrug-resistant Gram-negative bacteria: incidence and risk factors within a long-term care population. Infect Control Hosp Epidemiol. 2010;31:1148-53.

30. Furuno JP, Shurland SM, Zhan M, Johnson JK, Venezia RA, Harris AD, et al. Comparison of the methicillin-resistant Staphylococcus aureus acquisition among rehabilitation and nursing home residents. Infect Control Hosp Epidemiol. 2011;32: 244-9.

31. Stone ND, Lewis DR, Johnson TM, Hartney T, Chandler D, Byrd-Sellers J, et al. Methicillin-resistant Staphylococcus aureus (MRSA) nasal carriage in residents of Veterans Affairs longterm care facilities: role of antimicrobial exposure and MRSA acquisition. Infect Control Hosp Epidemiol. 2012;33:551-7.

32. Fisch J, Lansing B, Wang L, Symons K, Cherian K, McNamara $\mathrm{S}$, et al. New acquisition of antibiotic-resistant organisms in skilled nursing facilities. J Clin Microbiol. 2012;50:1698-703.

33. Lee BY, Song Y, Bartsch SM, Kim DS, Singh A, Avery TR, et al. Long-term care facilities: important participants of the acute care facility social network? PLoS One. 2011;6:e29342.

34. Zimmer JG, Bentley DW, Valenti WM, Watson NM. Systemic antibiotic use in nursing homes: a quality assessment. J Am Geriatr Soc. 1986;34:703-10.

35. Pickering T, Gurwitz J, Zaleznik D, Noonan J, Avorn J. The appropriateness of oral fluoroquinolone-prescribing in the longterm care setting. J Am Geriatr Soc. 1994;42:28-32.

36. Loeb M, Simor AE, Landry L, Walter S, McArthur M, Duffy J, et al. Antibiotic use in Ontario facilities that provide chronic care. J Gen Intern Med. 2001;16:376-83.

37. Vergidis P, Hamer DH, Meydani SN, Dallal GE, Barlam TF. Patterns of antimicrobial use for respiratory tract infections in older residents of long-term care facilities. J Am Geriatr Soc. 2011;59:1093-8.

38. Hepburn MJ, Dooley DP, Skidmore PJ, Ellis MW, Starnes WF, Hasewinkle WC. Comparison of short-course (5 days) and standard (10 days) treatment for uncomplicated cellulitis. Arch Intern Med. 2004;164:1669-74.

39. Lutters M, Vogt-Ferrier NB. Antibiotic duration for treating uncomplicated, symptomatic lower urinary tract infections in elderly women. Cochrane Database Syst Rev. 2008;3: CD001535.

40. Dimopoulos G, Matthaiou DK, Karageorgopoulos DE, Grammatikos AP, Athanassa Z, Falagas ME. Short- versus longcourse antibacterial therapy for community-acquired pneumonia: a meta-analysis. Drugs. 2008;68:1841-54.

41. Dryden M, Johnson AP, Ashiru-Oredope D, Sharland M. Using antibiotics responsibly: right drug, right time, right dose, right duration. J Antimicrob Chemother. 2011;66:2441-3.

42. Walker S, McGeer A, Simor AE, Armstrong-Evans M, Loeb M. Why are antibiotics prescribed for asymptomatic bacteriuria in institutionalized elderly people? A qualitative study of physicians' and nurses' perceptions. CMAJ. 2000;163:273-7.

43. Schweizer AK, Hughes CM, Macauley DC, O'Neill C. Managing urinary tract infections in nursing homes: a qualitative assessment. Pharm World Sci. 2005;27:159-65.

44. Helton MR, van der Steen JT, Daaleman TP, Gamble GR, Ribbe MW. A cross-cultural study of physician treatment decisions for demented nursing home patients who develop pneumonia. Ann Fam Med. 2006;4:221-7.

45. Lim CJ, Kwong M, Stuart RL, Buising KL, Friedman ND, Bennett $\mathrm{N}$, et al. Antimicrobial stewardship in residential aged 
care facilities: need and readiness assessment. BMC Infect Dis. 2014;14:410.

46. Lim CJ, Kwong MW-L, Stuart RL, Buising KL, Friedman ND, Bennett NJ, et al. Antibiotic prescribing practice in residential aged care facilities - health care providers' perspectives. Med J Aust. 2014;201:98-102.

47. Kistler CE, Sloane PD, Platts-Mills TF, Beeber AS, Khandelwal $\mathrm{C}$, Weber DJ, et al. Challenges of antibiotic prescribing for assisted living residents: perspectives of providers, staff, residents, and family members. J Am Geriatr Soc. 2013;61:565-70.

48. Let's take an antibiotic timeout [Internet]. Centers for Disease Control and Prevention. Available from: http://blogs.cdc.gov/ safehealthcare/2010/11/16/let's-take-an-antibiotic-time-out/. Cited 15 Feb 2015.

49. Bassetti M, Paiva J-A, Masterton RG. The case for de-escalation in antimicrobial therapy: time to change our strategy in the management of septic shock? Intensive Care Med. 2014;40: 284-5.

50. van Dijk PTM, Mehr DR, Ooms ME, Madsen R, Petroski G, Frijters $\mathrm{DH}$, et al. Comorbidity and 1-year mortality risks in nursing home residents. J Am Geriatr Soc. 2005;53:660-5.

51. Zhang X, Decker FH, Luo H, Geiss LS, Pearson WS, Saaddine $\mathrm{JB}$, et al. Trends in the prevalence and comorbidities of diabetes mellitus in nursing home residents in the United States: 1995-2004. J Am Geriatr Soc. 2010;58:724-30.

52. Smith P, Bennett G, Bradley S, Drinka P, Lautenbach E, Marx J, et al. SHEA/APIC guideline: infection prevention and control in the long-term care facility. Infect Control Hosp Epidemiol. 2008;29:785-814

53. Mody L, Bradley SF, Galecki A, Olmsted RN, Fitzgerald JT, Kauffman CA, et al. Conceptual model for reducing infections and antimicrobial resistance in skilled nursing facilities: focusing on residents with indwelling devices. Clin Infect Dis. 2011;52:654-61.

54. Crnich CJ, Drinka P. Medical device-associated infections in the long-term care setting. Infect Dis Clin North Am. 2012;26: 143-64.

55. Resnick NM, Marcantonio ER. How should clinical care of the aged differ? Lancet. 1997;350:1157-8.

56. Juthani-Mehta M, Quagliarello V, Perrelli E, Towle V, Van Ness PH, Tinetti M. Clinical features to identify urinary tract infection in nursing home residents: a cohort study. J Am Geriatr Soc. 2009;57:963-70.

57. D'Agata E, Loeb MB, Mitchell SL. Challenges in assessing nursing home residents with advanced dementia for suspected urinary tract infections. J Am Geriatr Soc. 2013;61:62-6.

58. Nace DA, Drinka PJ, Crnich CJ. Clinical uncertainties in the approach to long term care residents with possible urinary tract infection. J Am Med Dir Assoc. 2014;15:133-9.

59. Sloane PD, Kistler C, Mitchell CM, Beeber AS, Bertrand RM, Edwards AS, et al. Role of body temperature in diagnosing bacterial infection in nursing home residents. J Am Geriatr Soc. 2014;62:135-40.

60. Loeb MB, Carusone SBC, Marrie TJ, Brazil K, Krueger P, Lohfeld L, et al. Interobserver reliability of radiologists' interpretations of mobile chest radiographs for nursing home-acquired pneumonia. J Am Med Dir Assoc. 2006;7:416-9.

61. Katz PR, Karuza J, Intrator O, Mor V. Nursing home physician specialists: a response to the workforce crisis in long-term care. Ann Intern Med. 2009;150:411-3.

62. Martin-Misener R, Donald F, Wickson-Griffiths A, AkhtarDanesh N, Ploeg J, Brazil K, et al. A mixed methods study of the work patterns of full-time nurse practitioners in nursing homes. J Clin Nurs. 2015;24(9-10):1327-37.

63. Shield RR, Wetle T, Teno J, Miller SC, Welch L. Physicians, "missing in action": family perspectives on physician and staffing problems in end-of-life care in the nursing home. J Am Geriatr Soc. 2005;53:1651-7.

64. Katz PR, Karuza J. Physician practice in the nursing home: missing in action or misunderstood. $\mathrm{J}$ Am Geriatr Soc. 2005;53:1826-8.

65. Katz P, Beam T, Brand F, Boyce K. Antibiotic use in the nursing home: physician practice patterns. Arch Intern Med. 1990;150: 1465-8.

66. Richards CL, Darradji M, Weinberg A, Ouslander JG. Antimicrobial use in post-acute care: a retrospective descriptive analysis in seven long-term care facilities in Georgia. J Am Med Dir Assoc. 2005;6:109-12.

67. Squillace MR, Remsburg RE, Harris-Kojetin LD, Bercovitz A, Rosenoff E, Han B. The National Nursing Assistant Survey: improving the evidence base for policy initiatives to strengthen the certified nursing assistant workforce. Gerontologist. 2009; 49:185-97.

68. Zweig S, Lawhorne L. AMDA symposium. Improving the quality of nurse assistants in nursing homes: report of an attending physician survey and an AMDA symposium. J Am Med Dir Assoc. 2001;2:141-5.

69. Kim H, Harrington C, Greene WH. Registered nurse staffing mix and quality of care in nursing homes: a longitudinal analysis. Gerontologist. 2009;49:81-90.

70. Roberts TJ, Nolet KA, Bowers BJ. Consistent assignment of nursing staff to residents in nursing homes: a critical review of conceptual and methodological issues. Gerontologist. 2015; 55(3):434-47.

71. Castle NG, Engberg J. Staff turnover and quality of care in nursing homes. Med Care. 2005;43:616-26.

72. Miller DB, Brimigion J, Keller D, Woodruff S. Nurse-physician communication in a nursing home setting. Gerontologist. 1972;12:225-9.

73. Kayser-Jones JS, Wiener CL, Barbaccia JC. Factors contributing to the hospitalization of nursing home residents. Gerontologist. 1989;29:502-10.

74. Cadogan MP, Franzi C, Osterweil D, Hill T. Barriers to effective communication in skilled nursing facilities: differences in perception between nurses and physicians. J Am Geriatr Soc. 1999;47:71-5.

75. Eraker SA, Eeckhoudt LR, Vanbutsele RJ, Lebrun TC, Sailly JC. To test or not to test- to treat or not to treat: the decisionthreshold approach to patient management. J Gen Intern Med. 1986;1:177-82.

76. Djulbegovic B, Hozo I, Beckstead J, Tsalatsanis A, Pauker SG. Dual processing model of medical decision-making. BMC Med Inform Decis Making. 2012;12:94.

77. Nicolle LE. Antimicrobial stewardship in long term care facilities: what is effective? Antimicrob Resist Infect Control. 2014;3:6.

78. Rhee SM, Stone ND. Antimicrobial stewardship in long-term care facilities. Infect Dis Clin North Am. 2014;28:237-46.

79. Lim CJ, Kong DCM, Stuart RL. Reducing inappropriate antibiotic prescribing in the residential care setting: current perspectives. Clin Interv Aging. 2014;9:165-77.

80. Loeb M, Brazil K, Lohfeld L, McGeer A, Simor A, Stevenson $\mathrm{K}$, et al. Effect of a multifaceted intervention on number of antimicrobial prescriptions for suspected urinary tract infections in residents of nursing homes: cluster randomised controlled trial. BMJ. 2005;331:669.

81. Schwartz DN, Abiad H, DeMarais PL, Armeanu E, Trick WE, Wang Y, et al. An educational intervention to improve antimicrobial use in a hospital-based long-term care facility. J Am Geriatr Soc. 2007;55:1236-42.

82. Zabarsky TF, Sethi AK, Donskey CJ. Sustained reduction in inappropriate treatment of asymptomatic bacteriuria in a long- 
term care facility through an educational intervention. Am J Infect Control. 2008;36:476-80.

83. Pettersson E, Vernby A, Mölstad S, Lundborg CS. Can a multifaceted educational intervention targeting both nurses and physicians change the prescribing of antibiotics to nursing home residents? A cluster randomized controlled trial. J Antimicrob Chemother. 2011;66:2659-66.

84. Frentzel E, Moudouni DKM, Garfinkel S, Phillips C, Zhao H, Fuchs S. Standardizing antibiotic use in long-term care settings (SAUL study): final report. Agency for Healthcare Research and Quality Accelerating (AHRQ) ACTION Contract No. 290-2006000-191, Task Order No. 8. American Institutes for Research, Texas A\&M University School of Rural Public Health, and TMF Health Quality Institute; 2013.

85. Zimmerman S, Sloane PD, Bertrand R, Olsho LEW, Beeber A, Kistler C, et al. Successfully reducing antibiotic prescribing in nursing homes. J Am Geriatr Soc. 2014;62:907-12.

86. Doron S, McElroy N, Salem-Schatz S, Griswold P, Pallin DJ, Kandel R, et al. Improved practice and decreased antibiotic utilization for urinary indications in long term care facilities after an educational intervention. Poster presentation at: IDWeek 2014 (Abstract \#140). 2014.

87. Trautner BW, Grigoryan L, Petersen NJ, Hysong S, Cadena J, Petterson JE, et al. An innovative and successful antimicrobial stewardship approach to asymptomatic bacteriuria. JAMA Intern Med. 2015;175(7):1120-7.

88. Naughton BJ, Mylotte JM, Ramadan F, Karuza J, Priore RL. Antibiotic use, hospital admissions, and mortality before and after implementing guidelines for nursing home-acquired pneumonia. J Am Geriatr Soc. 2001;49:1020-4.

89. Monette J, Miller M, Monette M, Laurier C, Boivin J-F, Sourial $\mathrm{N}$, et al. Effect of an educational intervention on optimizing antibiotic prescribing in long-term care facilities. J Am Geriatr Soc. 2007;55:1231-5.

90. Linnebur SA, Fish DN, Ruscin JM, Radcliff TA, Oman KS, Fink $\mathrm{R}$, et al. Impact of a multidisciplinary intervention on antibiotic use for nursing home-acquired pneumonia. Am J Geriatr Pharmacother. 2011;9(442-450):e1.

91. Furuno JP, Comer AC, Johnson JK, Rosenberg JH, Moore SL, MacKenzie TD, et al. Using antibiograms to improve antibiotic prescribing in skilled nursing facilities. Infect Control Hosp Epidemiol. 2014;35(Suppl 3):S56-61.

92. Latour K, Catry B, Broex E, Vankerckhoven V, Muller A, Stroobants R, et al. Indications for antimicrobial prescribing in European nursing homes: results from a point prevalence survey. Pharmacoepidemiol Drug Saf. 2012;21:937-44.

93. Olsho LEW, Bertrand RM, Edwards AS, Hadden LS, Morefield GB, Hurd D, et al. Does adherence to the Loeb minimum criteria reduce antibiotic prescribing rates in nursing homes? J Am Med Dir Assoc. 2013;14(309):e1-7.

94. Crnich CJ, Drinka P. Improving the management of urinary tract infections in nursing homes: it's time to stop the tail from wagging the dog. Ann: Long Term Care; 2014. p. 43-7.

95. Nicolle LE, Long-Term-Care SHEA. Committee. Urinary tract infections in long-term-care facilities. Infect Control Hosp Epidemiol. 2001;22:167-75.

96. Ducharme J, Neilson S, Ginn JL. Can urine cultures and reagent test strips be used to diagnose urinary tract infection in elderly emergency department patients without focal urinary symptoms? CJEM. 2007;9:87-92.

97. Arinzon Z, Peisakh A, Shuval I, Shabat S, Berner YN. Detection of urinary tract infection (UTI) in long-term care setting: Is the multireagent strip an adequate diagnostic tool? Arch Gerontol Geriatr. 2009;48:227-31.
98. Phillips CD, Adepoju O, Stone N, Moudouni DKM, Nwaiwu O, Zhao $\mathrm{H}$, et al. Asymptomatic bacteriuria, antibiotic use, and suspected urinary tract infections in four nursing homes. BMC Geriatr. 2012;12:73.

99. Leis JA, Rebick GW, Daneman N, Gold WL, Poutanen SM, Lo $\mathrm{P}$, et al. Reducing antimicrobial therapy for asymptomatic bacteriuria among noncatheterized inpatients: a proof-of-concept study. Clin Infect Dis. 2014;58:980-3.

100. Lohfeld L, Loeb M, Brazil K. Evidence-based clinical pathways to manage urinary tract infections in long-term care facilities: a qualitative case study describing administrator and nursing staff views. J Am Med Dir Assoc. 2007;8:477-84.

101. Trautner BW, Bhimani RD, Amspoker AB, Hysong SJ, Garza A, Kelly PA, et al. Development and validation of an algorithm to recalibrate mental models and reduce diagnostic errors associated with catheter-associated bacteriuria. BMC Med Inform Decis Making. 2013;13:48.

102. High KP, Bradley SF, Gravenstein S, Mehr DR, Quagliarello VJ, Richards C, et al. Clinical practice guideline for the evaluation of fever and infection in older adult residents of long-term care facilities: 2008 update by the Infectious Diseases Society of America. Clin Infect Dis. 2009;48:149-71.

103. Schmidt IK, Svarstad BL. Nurse-physician communication and quality of drug use in Swedish nursing homes. Soc Sci Med. 2002;54:1767-77.

104. Ouslander JG, Lamb G, Perloe M, Givens JH, Kluge L, Rutland $\mathrm{T}$, et al. Potentially avoidable hospitalizations of nursing home residents: frequency, causes, and costs. J Am Geriatr Soc. 2010;58:627-35.

105. Grimshaw JM, Shirran L, Thomas R, Mowatt G, Fraser C, Bero $\mathrm{L}$, et al. Changing provider behavior: an overview of systematic reviews of interventions. Med Care. 2001;39:II2-45.

106. Pakyz AL, Moczygemba LR, Wang H, Stevens MP, Edmond MB. An evaluation of the association between an antimicrobial stewardship score and antimicrobial usage. J Antimicrob Chemother. 2015;70(5):1588-91.

107. Daneman N, Gruneir A, Bronskill SE, Newman A, Fischer HD, Rochon PA, et al. Prolonged antibiotic treatment in long-term care: role of the prescriber. JAMA Intern Med. 2013;173:673-82.

108. Peron EP, Hirsch AA, Jury LA, Jump RLP, Donskey CJ. Another setting for stewardship: high rate of unnecessary antimicrobial use in a veterans affairs long-term care facility. J Am Geriatr Soc. 2013;61:289-90.

109. Fleet E, Gopal Rao G, Patel B, Cookson B, Charlett A, Bowman $\mathrm{C}$, et al. Impact of implementation of a novel antimicrobial stewardship tool on antibiotic use in nursing homes: a prospective cluster randomized control pilot study. J Antimicrob Chemother. 2014;69:2265-73.

110. Jump RLP, Olds DM, Seifi N, Kypriotakis G, Jury LA, Peron $\mathrm{EP}$, et al. Effective antimicrobial stewardship in a long-term care facility through an infectious disease consultation service: keeping a LID on antibiotic use. Infect Control Hosp Epidemiol. 2012;33:1185-92.

111. Squires JE, Sullivan K, Eccles MP, Worswick J, Grimshaw JM. Are multifaceted interventions more effective than single-component interventions in changing health-care professionals' behaviours? An overview of systematic reviews. Implement Sci. 2014;9:152.

112. Castle NG, Zinn JS, Brannon D, Mor V. Quality improvement in nursing homes. Health Care Manag. 1997;3:39-54.

113. Dellefield ME, Kelly A, Schnelle JF. Quality assurance and performance improvement in nursing homes: using evidencebased protocols to observe nursing care processes in real time. J Nurs Care Qual. 2013;28:43-51. 
114. Dubberke ER, Olsen MA. Burden of Clostridium difficile on the healthcare system. Clin Infect Dis. 2012;55(Suppl 2):S88-92.

115. Fleming A, Bradley C, Cullinan S, Byrne S. Antibiotic prescribing in long-term care facilities: a qualitative, multidisciplinary investigation. BMJ Open. 2014;4:e006442.

116. Rantz MJ, Zwygart-Stauffacher M, Flesner M, Hicks L, Mehr D, Russell $\mathrm{T}$, et al. The influence of teams to sustain quality improvement in nursing homes that "need improvement". J Am Med Dir Assoc. 2013;14:48-52.

117. Wenisch JM, Equiluz-Bruck S, Fudel M, Reiter I, Schmid A, Singer E, et al. Decreasing Clostridium difficile infections by an antimicrobial stewardship program that reduces moxifloxacin use. Antimicrob Agents Chemother. 2014;58:5079-83.

118. Crnich CJ, Duster M, Hess T, Zimmerman DR, Drinka P. Antibiotic resistance in non-major metropolitan skilled nursing facilities: prevalence and interfacility variation. Infect Control Hosp Epidemiol. 2012;33(11):1172-4.

119. Drinka P, Podzorski RP, Griffin V, Crnich CJ. Antibiogram of urinary isolates. J Am Med Dir Assoc. 2013;14:443.

120. Pronovost PJ, Berenholtz SM, Needham DM. Translating evidence into practice: a model for large scale knowledge translation. BMJ. 2008;337:a1714.

121. Stone ND, Ashraf MS, Calder J, Crnich CJ, Crossley K, Drinka $\mathrm{PJ}$, et al. Surveillance definitions of infections in long-term care facilities: revisiting the McGeer Criteria. Infect Control Hosp Epidemiol. 2012;33:965-77.

122. Loeb M, Bentley DW, Bradley S, Crossley K, Garibaldi R, Gantz N, et al. Development of minimum criteria for the initiation of antibiotics in residents of long-term-care facilities: results of a consensus conference. Infect Control Hosp Epidemiol. 2001;22:120-4.

123. Gase KA, Haley VB, Xiong K, Van Antwerpen C, Stricof RL. Comparison of 2 Clostridium difficile surveillance methods:
National Healthcare Safety Network's laboratory-identified event reporting module versus clinical infection surveillance. Infect Control Hosp Epidemiol. 2013;34:284-90.

124. Han A, Jump RLP. Discrepancies between surveillance definition and the clinical incidence of Clostridium difficile infection in a Veterans Affairs long-term care facility. Infect Control Hosp Epidemiol. 2014;35:1435-6.

125. Dwyer LL, Harris-Kojetin LD, Valverde RH, Frazier JM, Simon $\mathrm{AE}$, Stone ND, et al. Infections in long-term care populations in the United States. J Am Geriatr Soc. 2013;61:342-9.

126. Fisch J, McNamara SE, Lansing BJ, Mody L. The 24-hour report as an effective monitoring and communication tool in infection prevention and control in nursing homes. Am J Infect Control. 2014;42:1112-4.

127. Mylotte JM, Keagle J. Benchmarks for antibiotic use and cost in long-term care. J Am Geriatr Soc. 2005;53:1117-22.

128. Polk RE, Fox C, Mahoney A, Letcavage J, MacDougall C. Measurement of adult antibacterial drug use in 130 US hospitals: comparison of defined daily dose and days of therapy. Clin Infect Dis. 2007;44:664-70.

129. Mody L, Krein SL, Saint SK, Min LC, Montoya A, Lansing B, et al. A targeted infection prevention intervention in nursing home residents with indwelling devices: a randomized clinical trial. JAMA Intern Med. 2015;175(5):714-23.

130. Juthani-Mehta M, Tinetti M, Perrelli E, Towle V, Quagliarello $\mathrm{V}$. Role of dipstick testing in the evaluation of urinary tract infection in nursing home residents. Infect Control Hosp Epidemiol. 2007;28:889-91.

131. Sundvall P-D, Gunnarsson RK. Evaluation of dipstick analysis among elderly residents to detect bacteriuria: a cross-sectional study in 32 nursing homes. BMC Geriatr. 2009;9:32. 